\title{
Practice Features Associated With Patient- Reported Accessibility, Continuity, and Coordination of Primary Health Care
}

Jeannie L. Haggerty, $P b D^{1}$

Raynald Pineault, $M D, P b D^{2}$

Marie-Dominique

Beaulieu, MD, MSc ${ }^{3}$

Yvon Brunelle, $M A^{4}$

Josée Gauthier, MSc ${ }^{5}$

François Goulet, $M D^{6}$

Jean Rodrigue, $M D^{7}$

'Département de Sciences de la Santé Communautaire, Université de Sherbrooke,

Longueuil, Québec, Canada

${ }^{2}$ Département de Médecine Sociale et Préventive, Université de Montréal, Montréal, Québec, Canada

${ }^{3}$ Département de Médecine Familiale, Université de Montréal, Montréal, Québec, Canada

${ }^{4}$ Ministère de la Santé et de Services Sociaux du Québec, Québec City, Québec, Canada

${ }^{5}$ Institut National de Santé Publique du Québec, Rimouski, Québec, Canada

${ }^{6}$ Practice Enhancement Division, Collège des Médecins du Québec, Montréal, Canada

${ }^{7}$ Fédération des Omnipraticiens du Québec, Montérégie, Quebec, Canada

\section{CORRESPONDING AUTHOR}

Jeannie L. Haggerty, PhD Université de Sherbrooke Centre de Recherche Hôpital Charles LeMoyne

Complexe St-Charles, Bureau 354, Tour Est 1111, Rue St-Charles Ouest Longueuil, QC J4K 5G4, Canada

Jeannie.Haggerty@usherbrooke.ca

\begin{abstract}
PURPOSE On the eve of major primary health care reforms, we conducted a multilevel survey of primary health care clinics to identify attributes of clinic organization and physician practice that predict accessibility, continuity, and coordination of care as experienced by patients.

METHODS Primary health care clinics were selected by stratified random sampling in urban, suburban, rural, and remote locations in Quebec, Canada. Up to 4 family or general physicians were selected in each clinic, and 20 patients seeing each physician used the Primary Care Assessment Tool to report on first-contact accessibility (being able to obtain care promptly for sudden illness), relational continuity (having an ongoing relationship with a physician who knew their particulars), and coordination continuity (having coordination between their physician and specialists). Physicians reported on aspects of their practice, and secretaries and directors reported on organizational features of the clinic. We used hierarchical regression modeling on the subsample of regular patients at the clinic.
\end{abstract}

RESULTS One hundred clinics participated (61\% response rate), for a total of 221 physicians and 2,725 regular patients (87\% response and completion rate). Firstcontact accessibility was most problematic. Such accessibility was better in clinics with 10 or fewer physicians, a nurse, telephone access 24 hours a day and 7 days a week, operational agreements to facilitate care with other health care establishments, and evening walk-in services. Operational agreements and evening care also positively affected relational continuity. Physicians who valued continuity and felt attached to the community fostered better relational continuity, whereas an accessibility-oriented style (as indicated by a high proportion of walk-in care and high patient volume) hindered it. Coordination continuity was also associated with more operational agreements and continuous telephone access, and was better when physicians practiced part time in hospitals and performed a larger range of medical procedures in their office.

CONCLUSIONS The way a clinic is organized allows physicians to achieve both accessibility and continuity rather than one or the other. Features that achieve both are offering care in the evenings and access to telephone advice, and having operational agreements with other health care establishments.

Ann Fam Med 2008;6:116-123. DOI: 10.1370/afm.802.

\section{INTRODUCTION}

I $\mathrm{n}$ Quebec —as in the rest of Canada_primary care is delivered principally by independent, physician-run practices, supported as private practices through reimbursement for medically necessary services on a fee-for-service basis. Approximately 15\% of primary health care in Quebec is delivered in territorially based community health centers (CLSCs) that receive block funding and have salaried personnel who deliver health and social services. These 2 subsystems have operated in parallel, and their independent functioning is considered to be an important cause of 
the problems in accessibility and continuity of care that have been highlighted in a recent health care commission. ${ }^{1}$

In 2002, Family Medicine Groups (FMGs) were proposed as a new organizational model to enhance integration between private practices and community health centers. The FMG is a volunteer administrative arrangement for existing practices or networks of 8 to 10 physicians who are accredited by the regional health authority to provide a basket of planned services, have extended service hours (including evenings, Saturdays, and Sundays), and have formal agreements with other establishments to offer the full range of services to a population of registered patients. In turn, the FMG receives 1 or more nurses paid from the budget of the local community health center. These organizational features are similar to those of primary health care models that are being introduced throughout Canada in an effort to strengthen primary health care.

In 2002, we conducted a survey to measure firstcontact accessibility and continuity as perceived by primary care patients and to identify characteristics of clinic organization and physician practice that explain the observed variance in these attributes. Continuity refers to both relational continuity between the patient and physician and to care continuity between the family physician and specialist, which we refer to as coordination continuity. The goal was not only to inform policy content for FMGs but also to guide decisions within the independent, physician-led practices that continue to be the predominant primary care model.

\section{METHODS}

\section{Study Population}

We conducted a cross-sectional, multilevel survey of 100 primary care clinics selected by stratified random sampling to have $75 \%$ private group practices, $10 \%$ solo practices, and $15 \%$ community health centers within urban, suburban, rural, and remote strata in Quebec, Canada. Eligible sites offered general medical services to an undifferentiated clientele, had not had major organizational changes in the last year, and had more than two-thirds of patients who could respond in English or French.

In clinics with 2 or fewer physicians, we selected all physicians, and in clinics with 3 or more physicians we selected 2 to 4 family or general physicians, depending on the clinic size. This approach maximized our statistical efficiency to detect effects at the clinic and physician levels. 2 Physician selection varied by site, from those who volunteered to those who were available on data collection days. Eligible physicians practiced general medicine on site at least
1 day per week and had worked at the clinic for at least 1 year. We recruited from the waiting room 20 consecutive patients consulting the selected physician. Data collection sometimes spanned multiple days, but was stopped if 20 patients were not recruited after 5 recruitment efforts on different days.

\section{Information Collected}

We collected information on accessibility, relational continuity, and coordination continuity from patients; on practice profiles from physicians; and on clinic organizational features from administrators and directors. The information was collected with self-administered questionnaires that had closed-ended questions and were validated in French and English. Research technicians administered the study on site, made observations, and obtained information from secretarial staff.

\section{Dependent Variables: Patient Assessment of Accessibility and Continuity}

We assessed patients' experience of first-contact accessibility and continuity principally by using the adult and child versions of the Primary Care Assessment Tool (PCAT). ${ }^{3,4}$ We selected this instrument because it has both patient and clinician versions. Parents reported on care received by children. All questions relate to the patient's regular care clinician or-for those without one-to the physician or clinic consulted that day. The conceptual and operational definitions of first-contact accessibility, relational continuity, and coordination continuity are provided in Table 1 . The scales represent the patient's confidence in being seen within a day for a sudden sickness (first-contact accessibility), in the clinician's knowledge of the patient's medical history and personal situation and in ongoing care (relational continuity), and in the coordination of care with the last specialist seen (coordination continuity). Each item asks the patient to estimate the likelihood of a positive aspect of care, with a response scale of 1 indicating definitely not ${ }_{i}$, probably not; 3 , probably; and 4, definitely. We averaged the item scores for each validated scale (range, 1-4). We established a mean score of 3 (probably) as the minimum expected level for each dimension of care. The extent to which a clinic was above or below the expected minimum was based on the mean of patient responses for that clinic.

Independent Variables: Physician and Clinic Characteristics

For each participating patient, the study physicians completed an encounter form indicating whether they were the principal responsible physician for that patient (affiliation), and if not, whether and how information 
Table 1. Definitions of Accessibility and Continuity of Primary Health Care

\begin{tabular}{|c|c|}
\hline Conceptual Definition & $\begin{array}{l}\text { Operational Definition of Minimal } \\
\text { Expectation (PCAT Subscale) }\end{array}$ \\
\hline $\begin{array}{l}\text { First-contact accessibility: the ability of a } \\
\text { person to obtain needed care (including } \\
\text { advice and support) from the practitio- } \\
\text { ner of choice within a time frame appro- } \\
\text { priate to the urgency of the problem }{ }^{20}\end{array}$ & $\begin{array}{l}\text { Patients should express confidence that they } \\
\text { could probably get advice or be seen within } 1 \\
\text { day by someone at their regular clinic if they } \\
\text { suddenly get sick and need care. (First-Contact } \\
\text { Access PCAT subscale, } 4 \text { items) }\end{array}$ \\
\hline \multirow{2}{*}{$\begin{array}{l}\text { Relational continuity: a therapeutic rela- } \\
\text { tionship with a practitioner that spans } \\
\text { more than } 1 \text { episode of care and leads, } \\
\text { in the practitioner, to a sense of clini- } \\
\text { cal responsibility and an accumulated } \\
\text { knowledge of the patient's personal and } \\
\text { medical circumstances }\end{array}$} & $\begin{array}{l}\text { Accumulated knowledge: patients should express } \\
\text { confidence that their physician probably knows } \\
\text { their medical history and personal situation. } \\
\text { (Ongoing Care PCAT subscale, } 8 \text { items) }\end{array}$ \\
\hline & $\begin{array}{l}\text { Clinical responsibility: patients should express con- } \\
\text { fidence that their physician's clinical responsibil- } \\
\text { ity probably extends beyond the clinical encoun- } \\
\text { ter. (Ongoing Care PCAT subscale, } 4 \text { items) }\end{array}$ \\
\hline $\begin{array}{l}\text { Coordination continuity: the delivery of } \\
\text { services by different practitioners in a } \\
\text { timely and complementary manner so } \\
\text { that care is connected and cohesive for } \\
\text { the patient }{ }^{5}\end{array}$ & $\begin{array}{l}\text { Patients should express confidence that their } \\
\text { primary care physician and the specialists }{ }^{\mathrm{a}} \text { com- } \\
\text { municate and collaborate in their care. (Coordi- } \\
\text { nation PCAT subscale, } 8 \text { items) }\end{array}$ \\
\hline
\end{tabular}

of the data structure, we used the HLM multilevel software ${ }^{12}$ to build 3-level, random-intercept hierarchical regression models, with clinics at level 3, physicians at level 2, and patients at level 1 , and allowing the intercept for each clinic to vary rather than be fixed as in ordinary least squares regression. We partitioned the total variance for each outcome into proportions attributed to clinic and physician levels of the data structure in an empty model, and then estimated how much of the clinic- and physician-level variance was explained by the respective variables included in the final model. Continuous variables were centered at the mean so that the intercept reflected the mean for all clinics and unit

would be communicated to the responsible physician (informational continuity). Physicians also completed the clinician version of the PCAT6,7 and reported on their practice profile (years in practice, practice sites, average hours per week at the clinic, weekly patient volume, acceptance of new patients, number and type of medical procedures performed), 8 degree of integration in the practice organization, and practice culture. The secretary provided their third next available appointment, most recent hourly patient volume, and preferred modalities for handling urgent care needs.

Practice administrators or medical directors reported on organizational attributes of the clinic: physical and human resources, governance and management structures, the number of health care establishments with which they had operational agreements, and practice culture. The measure of practice culture, inspired from various sources, ${ }^{9-11}$ was the mean of respondents' assessments of importance (on a 5-point scale) given to rapid access, psychosocial care management, customer service orientation, and business viability of the practice.

\section{Analysis}

Only patients whose regular clinician was a participating physician were included in this analysis. We built separate linear regression models for each outcome of interest in which the score for first-contact accessibility, relational continuity, or coordination continuity was the dependent variable and the variables related to clinic organization and physician practice were the independent variables. Considering the nested nature changes were meaningful below and above the mean. All models controlled for patient age, education, and use of primary care services in the past year.

We characterized the independent variables into 4 blocks relating to vision (practice culture), resource structure (number and type of physical and health human resources, hours during which the clinic was open, services offered), governance mechanisms (management structures and processes), and physician practice (availability at the clinic, information continuity, patient volume). ${ }^{13,14}$ We used stepwise regression analysis to identify the strongest variables in each conceptual block of variables, then added blocks in the order presented above. Building a stable regression model is challenging because, by definition, organizational dimensions are highly correlated in functional models. When attributes from different dimensions were too highly correlated to contribute independently, we selected the variable with the strongest association that was also modifiable.

\section{RESULTS}

Among 201 clinics randomly selected, 171 were eligible. Of clinics invited to participate, 64\% (110) accepted, but after data collection started, 3 withdrew and 7 were judged to be ineligible because more than one-third of their clientele could not complete the questionnaire in English or French. The final clinic participation rate was $61 \%$ (100 of 164 eligible). The characteristics of the 100 clinics are presented in Table 2 .

The 221 physicians contributed an average of 
18 patients (median, 20) in private practices and 12 patients (median, 12) in community health centers (CLSCs). Of the 4,764 contacted patients, 93\% were eligible and $89 \%$ participated, but only $87 \%$ provided complete information. Of these, 2,725 were included

\begin{tabular}{|c|c|}
\hline Characteristic & Percent \\
\hline \multicolumn{2}{|l|}{ Type } \\
\hline Private group practice & 57 \\
\hline Private solo practice & 16 \\
\hline Stand-alone, walk-in clinic & 10 \\
\hline Community health center (CLSC) & 17 \\
\hline \multicolumn{2}{|l|}{ Location } \\
\hline Urban & 38 \\
\hline Suburban & 22 \\
\hline Rural & 24 \\
\hline Remote & 16 \\
\hline Have a nurse on site & 39 \\
\hline Have an occupational or physical therapist on site & 25 \\
\hline $\begin{array}{l}\text { Offer } 24 / 7 \text { telephone access other than provincial } \\
\text { nurse help-line }\end{array}$ & 7 \\
\hline \multicolumn{2}{|l|}{ Offer walk-in services } \\
\hline None & 26 \\
\hline Daytime only & 36 \\
\hline Daytime and evening & 11 \\
\hline Daytime, evening, and weekends & 27 \\
\hline \multicolumn{2}{|l|}{ Offer scheduled visits during } \\
\hline Evenings & 48 \\
\hline Weekends & 13 \\
\hline \multicolumn{2}{|l|}{$\begin{array}{l}\text { No. of other health care establishments with which } \\
\text { the clinic has formal, operational agreements }\end{array}$} \\
\hline 0 & 53 \\
\hline 1 & 14 \\
\hline 2 & 15 \\
\hline 3 & 15 \\
\hline 4 & 3 \\
\hline
\end{tabular}

Table 3. Percentage by Which PCAT Scores Were Above or Below the Minimal Expected Standard Score of 3 at Various Levels for Each Dimension ( $\mathrm{N}=100$ Clinics)

\begin{tabular}{lccccc}
\hline & \multicolumn{5}{c}{ Level } \\
\cline { 2 - 6 } Dimension & Mean & Minimum & $\begin{array}{c}\text { 25th } \\
\text { Percentile }\end{array}$ & $\begin{array}{c}\text { 75th } \\
\text { Percentile }\end{array}$ & Maximum \\
\hline $\begin{array}{c}\text { First-contact } \\
\text { accessibility }\end{array}$ & $-35(2.30)$ & $-68(1.63)$ & $-44(2.11)$ & $-29(2.41)$ & $85(3.85)$ \\
$\begin{array}{c}\text { Relational } \\
\text { continuity }\end{array}$ & $36(3.35)$ & $-13(2.72)$ & $27(3.26)$ & $48(3.47)$ & $76(3.76)$ \\
$\begin{array}{c}\text { Coordination } \\
\text { continuity }\end{array}$ & $30(3.30)$ & $-34(2.31)$ & $15(3.13)$ & $49(3.49)$ & $100(4.00)$ \\
\hline
\end{tabular}

PCAT $=$ Primary Care Assessment Tool.

Note: Values are expressed as percentage above or below minimal PCAT score. A PCAT score of 3 (probably) is the minimal threshold; a score of 1 (definitely not) would be $-100 \%$ below minimal expectation, and a score of 4 (definitely) would be $+100 \%$ above minimal. For example, for firstcontact accessibility, the mean score of 2.30 was $35 \%$ below the minimal expected standard of 3 . in this analysis because their regular physician was a participating physician.

Table 3 shows average PCAT scores for all clinics as well as performance relative to the minimum expected for each measure. Results for each patientreported measure of care are detailed below.

\section{First-Contact Accessibility}

The most problematic aspect of care from patients' perspective was first-contact accessibility. The mean score of 2.3 was $35 \%$ below the minimal expected standard of 3 , and the vast majority of clinics were below the minimal level: the lower limit of the 75 th percentile was 2.41 or $29 \%$ below minimal (Table 3). Only $10 \%$ of patients were confident that someone from their clinic would see or advise them within 1 day for a sudden illness. Indeed, the average waiting time for an appointment was 24 days (median, 19).

The single most important predictor of first-contact accessibility was offering telephone access to patients 24 hours a day, 7 days a week; such access was offered by $10 \%$ of urban private practices and all community health centers in remote areas. The final multilevel regression model for first-contact accessibility is presented in Table 4, with characteristics grouped according to clinic or physician level. Each coefficient is expressed as the mean difference in PCAT score associated with a unit change in the characteristic. The model effects are additive, so that the average clinic (score, 2.3) could meet expected accessibility levels by having a nurse on site $(0.12)$, offering continuous telephone service (0.30), offering evening walk-in care (0.07), and adjusting appointment scheduling so that appropriate cases could be seen within 1 week $(0.09): 2.3+0.12+0.30+0.07+0.09=2.88$. Increasing open hours would also increase access, but we found that the effect of each additional hour the clinic was open (0.008) was significant only after a threshold of 55 hours. Enhancing links with other health care establishments also positively influenced accessibility (0.03 for each establishment).

Patients in practices with more than 10 family physicians experienced a 0.21 point lower first-contact accessibility than their counterparts in clinics with 10 or fewer. Offering weekend walk-in services had no effect, whereas offering evening walk-in services increased accessibility, as noted above. This increase did not reach significance in the final model, but was significant before adding physician-level variables and was retained because it has implications for organizing practice. 
Patients of the $20 \%$ of physicians who were available for appointments within a week experienced higher first-contact accessibility (0.09), as did patients of physicians who had a high hourly volume of patients, with a 0.02 -point increase in accessibility for every patient above the mean of 3.4 patients per hour. Physicians who responded to urgent needs by meeting patients in the emergency department had a 0.17-point lower accessibility. On closer examination, this effect was principally attributable to physicians who spent less than one-half of their practice time at the clinic, a pattern occurring mainly in rural areas.

The partitioning of variance showed that more of the total observed variance in first-contact accessibility was attributed to between-clinic differences than to between-physician differences (20\% vs $3 \%$ ). The block of physician practice variables reduced betweenclinic variance rather than between-physician variance, suggesting that-despite their name - these variables reflect organizational rather than individual practice

\section{Table 4. Characteristics of Clinic Organization and Physician Practice} That Influence Patients' Confidence in First-Contact Accessibility ${ }^{a}$

\begin{tabular}{|c|c|}
\hline Characteristic & $\begin{array}{l}\text { Multivariate Regression } \\
\text { Coefficient }(95 \% \mathrm{Cl})\end{array}$ \\
\hline Mean first-contact accessibility for all clinics & $2.30(2.26$ to 2.33$)$ \\
\hline \multicolumn{2}{|l|}{ Clinic-level characteristics ${ }^{b}$} \\
\hline \multicolumn{2}{|l|}{ Practice culture } \\
\hline $\begin{array}{l}\text { Priority of rapid access (effect of 1-unit increase in the } \\
\text { importance at the clinic on a 5-point scale centered on the } \\
\text { average for all clinics) }\end{array}$ & 0.07 (0.01 to 0.14$)$ \\
\hline \multicolumn{2}{|l|}{ Clinic structure } \\
\hline More than 10 family physicians (compared with $\leq 10$ ) & $-0.21(-0.33$ to -0.09$)$ \\
\hline Presence of a nurse in the clinic (compared with no nurse) & $0.12(0.05$ to 0.19$)$ \\
\hline $\begin{array}{l}\text { Availability of } 24 / 7 \text { telephone access other than provincial } \\
\text { nurse help line }\end{array}$ & $0.30(0.10$ to 0.50$)$ \\
\hline $\begin{array}{l}\text { No. of other health care establishments with which the clinic } \\
\text { has formal, operational agreements (effect of each addi- } \\
\text { tional establishment) }\end{array}$ & $0.03(0.00$ to 0.06$)$ \\
\hline \multicolumn{2}{|l|}{ Clinic services } \\
\hline Availability of evening walk-in services & $0.07(0.00$ to 0.14$)$ \\
\hline Availability of weekend walk-in services & - \\
\hline $\begin{array}{l}\text { No. of hours open during the week above } 55 \text { hours (effect of } \\
\text { each additional hour) }\end{array}$ & $0.008(0.006$ to 0.010$)$ \\
\hline \multicolumn{2}{|l|}{ Physician-level characteristics ${ }^{c}$} \\
\hline Next appointment in less than 1 week (compared with $>1$ week) & $0.09(0.01$ to 0.17$)$ \\
\hline $\begin{array}{l}\text { No. of patients seen per hour (each additional patient above } \\
\text { the mean of } 3.4 \text { patients per hour) }\end{array}$ & $0.02(-0.1$ to 0.05$)$ \\
\hline $\begin{array}{l}\text { Manage urgent care by meeting patients at the hospital emer- } \\
\text { gency department }\end{array}$ & $-0.17(-0.25$ to -0.09$)$ \\
\hline \multicolumn{2}{|l|}{$\mathrm{Cl}=$ confidence interval. } \\
\hline \multicolumn{2}{|c|}{ Note: the overall adjusted $R^{2}=15.7 \%$} \\
\hline \multicolumn{2}{|c|}{$\begin{array}{l}\text { a Results of hierarchical regression modeling showing the impact on achievement of optimal first-contact acces- } \\
\text { sibility. The model controlled for patient age, education, and use of primary care. Only the clinic's regular } \\
\text { patients were included in the analysis }(\mathrm{N}=2,725) \text {. } \\
\text { b Some } 20.3 \% \text { of the variance in first-contact accessibility was attributed to between-clinic variance, of which } \\
77.1 \% \text { was explained by the final model. } \\
\text { ' Some } 3.2 \% \text { of the variance in first-contact accessibility was attributed to between-physician variance; physi- } \\
\text { cian-level characteristics decreased between-clinic variance but not between-physician variance. }\end{array}$} \\
\hline
\end{tabular}

styles; nonetheless, most of the variance in reported accessibility was due to random error and betweenpatient variance.

\section{Relational Continuity}

In contrast to the case for first-contact accessibility, the vast majority of clinics had higher-than-minimal relational continuity (Table 3). Despite apparent problems of accessibility, $77 \%$ of patients were consulting their regular physician, an independent corroboration of the importance of relational continuity to patients.

Our relational continuity model is presented in Table 5. The number of other establishments with which the clinic had operational and formal care agreements improved relational continuity $(0.03$ points each), as did offering scheduled visits in evenings $(0.05)$; the effect for weekends was not significant. The total variance in relational continuity attributed to between-clinic variance and betweenphysician variance was almost equivalent: $8.8 \%$ and $6.7 \%$, respectively.

We found that physician attachment to the practice community increased continuity (0.05), as did plans for informational continuity (0.09). A walkin care and high-volume practice style was associated with lower relational continuity. When more than $70 \%$ of a physician's practice consisted of walk-in care, relational continuity decreased by 0.14 points. Although higher patient volume increased accessibility, each additional patient over the mean of 3.4 per hour reduced relational continuity by 0.03 points.

\section{Coordination Continuity}

Patient-reported coordination continuity was above the defined minimum expectation (Table 3 ), but between-clinic variance was high.

Table 6 presents the impact of clinic organization and physician practice on perceived coordination continuity. Again, offering continuous telephone access (0.16) and having agreements with other health care establishments ( 0.04 points each) increased perceived coordination. 


\begin{tabular}{|c|c|}
\hline Characteristic & $\begin{array}{l}\text { Multivariate Regression } \\
\text { Coefficient }(95 \% \mathrm{Cl}) \\
\end{array}$ \\
\hline Mean relational continuity for all clinics & 3.35 (3.34 to 3.39$)$ \\
\hline \multicolumn{2}{|l|}{ Clinic-level characteristics ${ }^{b}$} \\
\hline \multicolumn{2}{|l|}{ Clinic structure } \\
\hline $\begin{array}{l}\text { No. of other health care establishments with which the clinic } \\
\text { has formal, operational agreements (effect of each addi- } \\
\text { tional establishment) }\end{array}$ & $0.03(0.00$ to 0.04$)$ \\
\hline \multicolumn{2}{|l|}{ Clinic services } \\
\hline Availability of scheduled visits in the evening & $0.05(-0.01$ to 0.10$)$ \\
\hline Availability of scheduled visits on weekends & - \\
\hline \multicolumn{2}{|l|}{ Physician-level characteristics ${ }^{c}$} \\
\hline \multicolumn{2}{|l|}{ Physician orientation } \\
\hline Attachment to the community served by the clinic & $0.05(0.02$ to 0.08$)$ \\
\hline $\begin{array}{l}\text { Physician intentions for informational continuity (communica- } \\
\text { tion of visit results to patient's responsible physician) }\end{array}$ & 0.09 (0.06 to 0.13$)$ \\
\hline \multicolumn{2}{|l|}{ Physician practice } \\
\hline $\begin{array}{l}\text { Percentage of clinic hours spent on walk-in care } \geq 70 \% \text { (com- } \\
\text { pared with }<50 \% \text { ) }\end{array}$ & $-0.14(-0.24$ to 0.05$)$ \\
\hline $\begin{array}{l}\text { No. of patients seen per hour (each additional patient above } \\
\text { the mean of } 3.4 \text { patients per hour) }\end{array}$ & $-0.03(-0.05$ to 0.00$)$ \\
\hline \multicolumn{2}{|l|}{$\mathrm{Cl}=$ confidence interval. } \\
\hline \multicolumn{2}{|l|}{ Note: the overall adjusted $R^{2}=15.9 \%$. } \\
\hline \multicolumn{2}{|c|}{$\begin{array}{l}\text { a Results of hierarchical regression modeling showing impact on achievement of optimal relational continuity. } \\
\text { The model controlled for patient age, education, and use of primary care. Only the physician's regular patients } \\
\text { were included }(N=2,725) \text {. }\end{array}$} \\
\hline \multicolumn{2}{|c|}{$\begin{array}{l}\text { b Some } 8.8 \% \text { of the variance in relational continuity was attributed to between-clinic variance, of which } 73.9 \% \\
\text { was explained by the final model. }\end{array}$} \\
\hline $\begin{array}{l}\text { ' Some } 6.7 \% \text { of the variance in relational continuity was attributed to betv } \\
40 \% \text { was explained by the final model. }\end{array}$ & en-physician variance, of which \\
\hline
\end{tabular}

\section{DISCUSSION}

We found that in Quebec in 2002, patients had little confidence in being able to promptly access their primary care provider for a sudden illness, but were generally confident in an ongoing relationship with their general physician, who knew their particulars, and in coordination of care between their general physician and specialists. Most importantly, we found that characteristics that are features of the proposed FMG models can be expected to improve these attributes of care: a group size of 8 to 10 physicians, the presence of a nurse, offering service in the evenings, having an information link to the nurse help line, and establishing formal arrangements for shared care with other establishments. Some of these features have been highlighted by other studies.15,16 Between 2002 and mid-2007, 127 FMGs were accredited by the Ministry of Health and Social Services to serve more than 1 million registered patients, and more are planned. Although only a small proportion of the population is covered formally by FMGs, they constitute a major sea change in the way that primary health care is delivered, and their use is expected to influence this delivery generally. A strength of this study is that it demonstrates how accessibility and continuity can be improved in clinics that are not FMGs.

The organizational feature common to higher accessibility, relational continuity, and coordination continuity is the number of other health care institutions with which the primary health care clinic has operational and formal agreements. Our initial questionnaire did not specify the nature of these agreements, so we asked clinics to describe them in more detail (73 clinics responded). These agreements were mostly shared-care protocols or mechanisms for facilitated referrals and information sharing. In community health centers, these tend to be formal agreements, but in physician-run practices, the agreements were based on social relationships. The degree of integration of primary care models has been identified as a crucial element of model effectiveness. ${ }^{14}$ The improvement in coordination of care that we observed when physi- 


\begin{tabular}{|c|c|}
\hline Characteristic & $\begin{array}{l}\text { Multivariate Regression } \\
\text { Coefficient }(95 \% \mathrm{Cl})\end{array}$ \\
\hline Mean coordination continuity for all patients & $3.30(2.28$ to 3.39$)$ \\
\hline \multicolumn{2}{|l|}{ Clinic-level characteristics ${ }^{b}$} \\
\hline \multicolumn{2}{|l|}{ Clinic structure } \\
\hline $\begin{array}{l}\text { Availability of } 24 / 7 \text { telephone access other than provincial } \\
\text { nurse help line }\end{array}$ & $0.16(0.04$ to 0.28$)$ \\
\hline $\begin{array}{l}\text { No. of other health care establishments with which the clinic } \\
\text { has formal, operational agreements (effect of each addi- } \\
\text { tional establishment) }\end{array}$ & 0.04 (0.04 to 0.07$)$ \\
\hline Presence of occupational and physical therapists & $0.12(0.03$ to 0.21$)$ \\
\hline \multicolumn{2}{|l|}{ Physician-level characteristicsc } \\
\hline $\begin{array}{l}\text { No. of medical procedures performed on site by the physician } \\
\text { (effect of each additional procedure above the mean of } 3.8 \text { ) }\end{array}$ & $0.02(0.00$ to 0.04$)$ \\
\hline Percentage of time spent in clinic is $<50 \%$ & - \\
\hline Percentage of time spent in clinic is $50 \%-70 \%$ & $0.09(-0.02$ to 0.23$)$ \\
\hline Percentage of time spent in clinic is $70 \%-90 \%$ & - \\
\hline \multicolumn{2}{|l|}{$\mathrm{Cl}=$ confidence interval. } \\
\hline \multicolumn{2}{|l|}{ Note: the overall adjusted $R^{2}=7.8 \%$. } \\
\hline \multicolumn{2}{|c|}{$\begin{array}{l}\text { a Results of hierarchical regression modeling showing impact on achievement of optimal coordination continu- } \\
\text { ity. The model controlled for patient age, education, and use of primary care. Only the physician's regular } \\
\text { patients who had seen a specialist in the last } 2 \text { years were included }(n=1,682) \text {. }\end{array}$} \\
\hline \multicolumn{2}{|c|}{$\begin{array}{l}\text { b Some } 2.4 \% \text { of the total variance in coordination continuity was explained by between-clinic variance, almost } \\
\text { all of which }(98 \%) \text { was explained by the final model. }\end{array}$} \\
\hline \multicolumn{2}{|c|}{$\begin{array}{l}\text { 'Some } 6.3 \% \text { of the total variance in coordination continuity was explained by between-physician variance, of } \\
\text { which } 79.6 \% \text { was explained by the final model. }\end{array}$} \\
\hline
\end{tabular}

cians worked in more than 1 setting may be due to a strengthening of the personal links with specialists.

Although other studies have found that patient assessments of access are lower than those for continuity, ${ }^{15}$ accessibility in our study was particularly problematic. The long wait for appointments was an independent validation of patient perceptions. The accessibility problem may not be unique to Quebec. In the national survey Access to Health Care Services, $18.8 \%$ of Canadians reported having difficulties in getting care for immediate health problems in 2001, 17,18 and this increased to $24.2 \%$ in $2003 .{ }^{17} \mathrm{~A}$ recent study showed Canadians waited longer for primary care appointments than patients in New Zealand, Australia, and the United Kingdom. ${ }^{19}$ Although changes in physician supply and practice style may explain part of the problem, our results provide direction for organizational changes to increase access for patients. Improving telephone access seems particularly critical; our study showed least satisfaction with the ability to get through to the clinic and to obtain needed advice. ${ }^{20}$ For clinics that cannot extend service hours over the minimal threshold of 55 hours per week, a redistribution of open hours to offer care in the evenings would enhance both accessibility and relational continuity. Integrating a nurse into the practice was associated with higher accessibility; our data did not allow us to specify what roles of the nurse enhance accessibility, but nurses' recognized strength in patient education may provide patients with confidence that they can obtain advice and orientation for new health problems.

Achieving balance between accessibility and continuity is a challenge for physicians, ${ }^{7,21,22}$ and it appears that most family physicians have organized their practice to maximize continuity at the expense of accessibility. Yet good accessibility is required to maintain continuity. Balance might be achieved by leaving space for urgent care between scheduled patients, varying according to time of year, and reserving advance appointments for nonurgent care. ${ }^{23}$

We expected that relational continuity would suffer in large physician groups, but surprisingly, accessibility did. Higher scores for accessibility in smaller practices have also been reported in studies in England. ${ }^{15,24}$ In large practices, patients may be less likely to see their own physician and consequently may perceive lower accessibility $_{i}$ their perceptions of health care may be more positive when they perceive their clinician's affiliation to be personal rather than institutional. ${ }^{14}$

Our study has some limitations. This is an exploratory study. Of the many variables significantly related to dimensions of care, we retained in the final model those we judged to be relevant to practice policies, but often this approach entailed choosing 1 among correlated variables so that the variable was a proxy for a cluster of features. For instance, physicians who spent more than $50 \%$ of their time in walk-in care also had a high hourly patient volume, performed a larger range of medical procedures, and tended not to be integrated in the management of the clinic. Some of these features were retained in the accessibility model, and some were retained in the continuity models, but the cluster of features would be related to both outcomes

Although we successfully explain a large proportion of between-clinic and between-physician difference, the overall variance explained by the models $\left(R^{2}\right)$ is small, indicating the presence of random error, measurement error, or both in patients' assessments of the attributes. Patients' assessments of one attribute seem to be influenced by other attributes. We found that satisfaction with waiting time for an appointment 
(data not shown) was more strongly correlated with relational continuity than with the reported time to the third next available appointment. Patients' assessments of clinic features such as access appear to be greatly influenced by interpersonal dimensions of care.

In conclusion, despite limitations, our study suggests concrete ways to organize and deliver primary health care for better accessibility and continuity, especially in the Canadian context. Many features of FMGs in Quebec should improve first-contact accessibility and both relational and coordination continuity of care. In particular, telephone access is a critical feature to improve, one that has been overlooked in many renewal initiatives to improve primary care.

To read or post commentaries in response to this article, see it online at http://www.annfammed.org/cgi/content/full/6/2/116.

Key words: Organization $\&$ administration; physician's practice patterns; accessibility of health services; continuity of patient care; coordination of patient care; primary health care; practice-based research

Submitted May 30, 2007; submitted, revised, August 21, 2007; accepted October 8, 2007.

Funding support: This study was funded by the Canadian Health Services Research Foundation; the Quebec Health Research Foundation (FRSQ); the regional health authority (Régie régionale de la Santé et des Services sociaux) of Montréal-Centre; and the Dr Sadok Besrour Research Chair in Family Medicine. Direct in-kind support was provided by Quebec National Institute of Public Health (INSPQ), Collège des médecins du Québec (Quebec College of Physicians), The Quebec Federation of General Practitioners (FMOQ), the regional health authorities of Bas-Saint-Laurent and Côte-Nord, and the Quebec Ministry of Health and Social Services (MSSS). During the period of this study, Jeannie Haggerty was appointed in the Department of Family Medicine at the Université de Montréal and was supported as a research scholar (Junior 1) by the Quebec Health Research Foundation (FRSQ). Marie-Dominique Beaulieu held the endowed chair of the Dr Sadok Besrour Research in Family Medicine.

\section{References}

1. Clair M. Commission d'Étude sur les Services de Santé et les Services Sociaux: Les Solutions Émergentes, Rapport et Recommandations. Quebec, Canada: Gouvernement du Québec; 2000.

2. Snijders T, Bosker R. Multi-Level Analysis: An Introduction to Basic and Advanced Multi-Level Modeling. Wiltshire, United Kingdom: Sage Publications; 1999.

3. Cassady CE, Starfield B, Hurtado MP, Berk RA, Nanda JP, Friedenberg LA. Measuring consumer experiences with primary care. Pediatrics. 2000;105(4):998-1003.

4. Shi L, Starfield B, Xu J. Validating the adult primary care assessment tool. J Fam Pract. 2001;50(2):161-171.
5. Haggerty JL, Reid RJ, Freeman GK, Starfield BH, Adair CE, McKendry R. Continuity of care: a multidisciplinary review. BMJ. 2003;327 (7425):1219-1221.

6. Starfield B, Cassady C, Nanda J, Forrest CB, Berk R. Consumer experiences and provider perceptions of the quality of primary care: implications for managed care. J Fam Pract. 1998;46(3):216-226.

7. Starfield B. Primary Care: Balancing Health Needs, Services, and Technology. New York, NY: Oxford University Press; 1998.

8. College of Family Physicians of Canada. Part of the JANUS Project: family physicians meeting the needs of tomorrow's society. 2001. http://www.cfpc.ca/English/cfpc/research/janus\%20project/default. asp?s=1. Accessed Oct 20, 2007.

9. Shortell SM, O’Brien JL, Carman JM, et al. Assessing the impact of continuous quality improvement/total quality management: concept versus implementation. Health Serv Res. 1995;30(2):377-401.

10. Kralewski JE, Wingert TD, Barbouche MH. Assessing the culture of medical group practices. Med Care. 1996;34(5):377-388.

11. Crabtree BF, Miller WL, Stange KC. Understanding practice from the ground up. J Fam Pract. 2001;50(10):881-887.

12. Raudenbush SW. HLM 5: Hierarchical Linear and Nonlinear Modeling. Version 5. Lincolnwood, IL: Scientific Software International, Inc; 2001.

13. Contandriopoulos AP, Denis JL, Touati N, Rodriguez R. Intégration des soins: dimensions et mise en oeuvre. Ruptures, Revue Transdisciplinaire en Santé. 2001;8(2):38-52.

14. Lamarche PA, Beaulieu M-D, Pineault R, Contandriopoulos A-P, Denis J-L, Haggerty J. Choices for Change: The Path for Restructuring Primary Healthcare Services in Canada. Ottawa, Ontario, Canada: Canadian Health Services Research Foundation; 2003:1-38.

15. Campbell SM, Hann M, Hacker J, et al. Identifying predictors of high quality care in English general practice: observational study. BMJ. 2001;323(7316):784-787.

16. Shi L, Starfield B, Xu J, Politzer R, Regan J. Primary care quality: community health center and health maintenance organization. South Med J. 2003;96(8):787-795.

17. Statistics Canada. Access to Health Services in Canada, 2003. Ottawa, Ontario, Canada: Statistics Canada; 2004. Publication 82-575-XIF.

18. Sanmartin C, Berthelot J-M, White K, Health Analysis and Measurement Group. Access to Health Care Services in Canada, 2001. Ottawa, Ontario, Canada: Statistics Canada; 2002;1-31. Publication 82-575-XIE.

19. Schoen C, Osborn R, Huynh PT, et al. Primary care and health system performance: adults' experiences in five countries. Health Aff (Millwood). 2004;Jul-Dec;Suppl Web Exclusives, W4:487-503.

20. Haggerty J, Martin CM. Evaluating Primary Health Care in Canada: The Right Questions to Ask! The National Evaluation Strategy for Primary Health Care. Ottawa, Ontario, Canada: Health Canada; 2005.

21. Freeman GK, Richards SC. Is personal continuity of care compatible with free choice of doctor? Patients' views on seeing the same doctor. Br J Gen Pract. 1993;43(377):493-497.

22. Safran DG. Defining the future of primary care: what can we learn from patients? Ann Intern Med. 2003;138(3):248-255.

23. Institute for Healthcare Improvement. Measures: Primary Care Access, Third Next Available Appointment. http://www.ihi.org/lHI/ Topics/OfficePractices/Access/Measures/. 2005. Accessed Feb 2008.

24. Campbell JL, Ramsay J, Green J. Practice size: impact on consultation length, workload, and patient assessment of care. $\mathrm{Br} J \mathrm{Gen}$ Pract. 2001;51(469):644-650. 